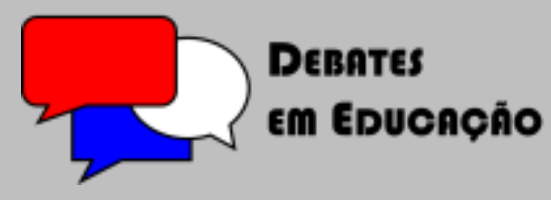

ISSN: $2175-6600$

Vol. 9 | №. 18 | Mai./Ago. | Ano 2017

Yana Liss Soares Gomes

Universidade Federal de Alagoas (UFAL)

yana.gomes@cedu.ufal.br

\section{CRENÇAS E VARIAÇÃO LINGUÍSTICA: UMA ANÁLISE SOB A ÓTICA DA COMPLEXIDADE}

\begin{abstract}
RESUMO
Neste artigo, discorremos sobre a natureza sistêmica das crenças a partir de um recorte de análise da nossa pesquisa de doutorado cujo objetivo foi analisar as crenças de formandos de Português e de Espanhol acerca da variação linguística. Partindo do paradigma da Complexidade, recorremos à Teoria do Caos/Complexidade para compreender a dinamicidade e a complexidade das crenças no âmbito do universo de formação de professor de línguas. Os pressupostos da Sociolinguística foram retomados para abordarmos alguns tópicos de contato entre o ensino de língua materna e o ensino de língua estrangeira. Através do cruzamento de alguns fatores observamos que as diversas crenças dos formandos relacionam-se de forma sistêmica, de tal modo que os diferentes elementos desse sistema, aparentemente desordenados, estruturam-se em redes que se organizam de forma mais central e/ou periférica.
\end{abstract}

Palavras-chave: Crenças. Variação linguística. Complexidade.

\section{BELIEFS AND LINGUISTIC VARIATION: AN ANALYSIS UNDER THE OPTICS OF COMPLEXITY}

\begin{abstract}
Based on part of my doctoral research whose objective was to analyse the beliefs of graduating students of Portuguese and Spanish. I discuss the systemic nature of beliefs in relation to linguistic variation. Beginning with the paradigm of Complexity, I make use of Caos/Complexity Theory to understand the dynamics and complexity of beliefs in the context of the formation of language teachers. Assumptions from Sociolinguistics were considered in order to approach some topics of contact between mother and foreign language teaching. By crossing some factors we observed that the various beliefs of graduating students relate themselves systemically, so that the different elements of this system, apparently disordered, are structured in networks that organize themselves in a more central and / or peripheral way.
\end{abstract}

Keywords: Beliefs. Linguistic variation. Complexity.

DOI: $10.28998 / 2175-6600.2017 v 9 n 18 p 45$ 


\section{INTRODUÇÃO}

A proposta deste artigo é refletir sobre a natureza sistêmica das crenças de formandos acerca da variação linguística na interface da formação de professores de língua materna (LM) e de língua estrangeira (LE), a partir de um recorte da nossa pesquisa de doutorado'.

Cabe esclarecer que, em virtude da abrangência desse estudo, adotamos uma perspectiva de Linguística Aplicada (LA) transdisciplinar ${ }^{2}$, considerando a linguagem como prática social e, consequentemente, a língua e seus diversos usos como processos dinâmicos e complexos.

Pelo viés da Complexidade, discorreremos sobre as crenças dos formandos e as inter-relações de componentes internos e externos à organização sistêmica e à formação de professores de línguas. O cruzamento de fatores identificados no âmbito das crenças acerca do estatuto das línguas, do seu caráter heterogêneo e de seu ensino foi crucial para investigarmos as crenças dos formandos que se relacionavam à variação linguística ${ }^{3}$.

A Teoria do Caos/Complexidade serviu de esteio para compreendermos alguns dos aspectos da natureza sistêmica das crenças no âmbito da formação de professores de línguas. Para tanto, selecionamos alguns tópicos de contato entre o ensino de LM e de LE, a saber: língua/linguagem, mitos linguísticos e diversidade linguística.

As reflexões apresentadas a seguir, permitem explicitar com mais objetividade, o ponto central da discussão deste artigo, a natureza sistêmica das crenças.

\section{A CIÊNCIA DA COMPLEXIDADE E A LINGUÍSTICA APLICADA (LA)}

A Complexidade originou-se da confluência de várias áreas, tais como: a Cibernética, a Inteligência Artificial, as Dinâmicas Não-lineares e Teoria dos Sistemas. Com o tempo, ela passou a ser considerada uma ciência de natureza global dos sistemas, rompendo as barreiras que distanciam as diversas áreas científicas. É, assim, inovadora, uma vez que propõe uma visão holística para um determinado fenômeno, incorporando a

\footnotetext{
1 Tese de doutorado defendida no Programa de Pós-Graduação em Estudos Linguísticos (POSLIN) da Universidade Federal de Minas Gerais (UFMG).

2 Essa perspectiva de LA não se limita à Linguística como componente teórico, uma vez que a finalidade é problematizar e compreender as questões de linguagem que atendam às necessidades das sociedades contemporâneas (LEFFA, 2006).

${ }^{3}$ Concebemos a variação linguística como toda e qualquer manifestação múltipla da língua ou fala que se materializa na interação e por sua natureza complexa, dinâmica e heterogênea traduz-se como conhecimento implícito, ou seja, como crenças sobre tudo que o cerca, inclusive sobre a língua e seus usos (GOMES, 2015).
} 
este a não linearidade, o dinamismo, a alta sensibilidade às condições iniciais, a autoorganização e a imprevisibilidade (BRAGA, 2007).

Para Mariotti (2007), a multiplicidade de interações dos sistemas complexos e dinâmicos só pode ser entendida por um novo paradigma, ou seja, por um pensamento aberto, abrangente e flexível, o Pensamento Complexo. Ele possibilita a elaboração de novos conhecimentos e práticas na busca de outras maneiras para compreender a complexidade dos sistemas naturais, o que evidentemente, inclui as relações humanas e suas culturas.

Assim, a Ciência da Complexidade diferencia-se da ciência tradicional determinística e hipotética, contrariando a lógica cartesiana (PAIVA, 2005). Portanto, não é de se estranhar que esse pensamento nos últimos anos, tenha sido aplicado em diversas áreas, como por exemplo, na Antropologia Social, na Educação e na Linguística Aplicada.

De acordo com Sade (2009), o interesse pela Complexidade dentro da Linguística Aplicada (LA) deu-se dentro do contexto contemporâneo em que, notadamente, as interações entre os sujeitos, grupos sociais e o surgimento de inúmeros discursos têm proporcionado investigar a dinamicidade e a imprevisibilidade das relações humanas.

No Brasil, inspirados pelo estudo pioneiro de Larsen-Freeman (1997), muitas pesquisas de LA têm utilizado o viés da Complexidade para investigar diferentes objetos, dentre os quais: aquisição de uma segunda língua, aprendizagem de língua estrangeira, comunidade de aprendizagem colaborativa on-line, dinâmicas interativas, construção de identidade, ensino de língua estrangeira e formação de professor de língua estrangeira. Esse quadro revela as inúmeras possibilidades de aplicação da Ciência da Complexidade nos estudos de LA.

Segundo Martins e Braga (2007), o paradigma da Complexidade, paulatinamente, tem se constituído uma base epistemológica consistente para a compreensão das atividades (eventos e contextos) referentes, sobretudo, ao ensino e a aprendizagem de língua estrangeira; por outro lado, diversas são as lacunas que ainda podem ser preenchidas sob o prisma dos sistemas complexos, especialmente por estudos que relacionem as crenças de alunos à formação de professor.

A seguir, apresentaremos os pressupostos da Teoria do Caos/Complexidade utilizados, nesta pesquisa, para o estudo da natureza sistêmica das crenças no âmbito da formação de professores de línguas (LM e de LE). 


\section{A TEORIA DO CAOS/COMPLEXIDADE E OS SISTEMAS COMPLEXOS}

A Teoria do Caos/Complexidade presente em diferentes áreas do conhecimento, como por exemplo, nas ciências humanas e na educação, tem sido muito usada nos estudos de Linguística Aplicada (LA). No Brasil, inúmeras pesquisas nessa área têm recorrido à ótica dos sistemas complexos e caóticos para analisar diferentes objetos de estudo.

Segundo Resende (2009), os pressupostos dessas duas teorias estão interligados e, por vezes, se confundem. Caos e complexidade são termos intercambiáveis, talvez, por isso, seja muito recorrente a intersecção entre a Teoria do Caos e a Teoria da Complexidade. A constituição semântica dos termos, caos e complexidade, é essencial para a construção do conhecimento científico pelo viés da Teoria do Caos/Complexidade.

Mas antes é preciso explicar que, embora sejam teorias afins, elas têm origens epistemológicas e propósitos diferentes. A Teoria do Caos surgiu nas ciências ditas "duras" (como a matemática e a física) com o objetivo de entender como os sistemas simples podem gerar comportamento "caótico"; enquanto que a Teoria da Complexidade tem suas raízes nas ciências biológicas, na química e economia e sua finalidade é compreender o comportamento dos sistemas complexos.

Conforme lembra Oliveira (2009), a visão da gênese dessas duas teorias forma um escopo conceitual e um campo de investigação bastante sólido em diversas ciências. A Teoria da Complexidade compartilha com a Teoria do Caos, o pensamento de que a sensibilidade dos fenômenos às condições iniciais pode resultar em alterações, aparentemente aleatórias, que se propagam por todo o sistema complexo (MASON, 2008).

Leffa (2006) destaca que a característica mais importante da Teoria do Caos é o entendimento acerca das condições iniciais. Assim, a metáfora do 'efeito borboleta' ${ }^{4}$ é usada para justificar a hipersensibilidade dos sistemas caóticos às suas condições iniciais. A Teoria da Complexidade, por sua vez, lida com comportamentos não previsíveis, aparentemente aleatórios, rompendo com a relação de causa/efeito proposta pelo paradigma positivista (RESENDE, 2009).

\footnotetext{
${ }^{4}$ Esse pensamento foi influenciado pelo estudo do meteorologista Edward Lorenz que, em 1963, cunhou o termo "efeito borboleta" para explicar a alta sensibilidade às condições iniciais dos sistemas. Lorenz, afirmava que em determinada parte do mundo, um simples bater de asas da borboleta pode transformar o clima de um local bem distante.
} 
Uma das principais contribuições da Teoria do Caos para o estudo de sistemas complexos é a definição de caos, que não pode ser concebido como sinônimo de desordem (LEFFA, 2006). A compreensão desse conceito nos possibilita entender como são formados os sistemas complexos, ou seja, aqueles sistemas que não obedecem a uma ordem determinista e que, por isso, não poderiam ser analisados pelos parâmetros positivistas da ciência clássica (SABOTA, 2008).

Os sistemas complexos são aqueles que possuem diferentes tipos de elementos, usualmente em grande número, que interagem constantemente de maneira diferenciada (BRAGA, 2009). Em geral, esses sistemas recebem esse nome pelo grande número de componentes que o constituem e pela maneira como eles agem e interagem dentro do próprio sistema (AUGUSTO, 2009).

Após discorremos sobre os pressupostos da Teoria do Caos/Complexidade e descrevermos aspectos das principais características dos sistemas complexos, apresentaremos o modelo utilizado neste estudo para investigar a natureza sistêmica das crenças dos formandos de Português e de Espanhol.

\section{AS CRENÇAS SOB A ÓTICA DA COMPLEXIDADE}

No campo da Linguística Aplicada (LA), o significado das crenças é bastante complexo, pois inúmeras são as definições usadas para representar esse termo (BARCELOS, 2008). A profusão de conceitos sobre crenças mostra o potencial desse construto para a LA, por outro lado, sinaliza a necessidade de se compreender a sua natureza e sua organização.

As crenças no contexto de ensino/aprendizagem de línguas, especialmente de língua estrangeira têm sido objeto de estudo de vários pesquisadores de LA. A esse respeito Borges e Fraga (2010), ponderam que, muito embora essas definições sejam diversas, por vezes, elas se assemelham e se relacionam à natureza da própria linguagem e ao ensino-aprendizagem de línguas, assim como estão ligadas às ideias e às percepções dos sujeitos, em determinado contexto cultural.

Neste estudo as crenças são concebidas como formas de pensamentos, isto é, "[...] construções da realidade, maneiras de ver e perceber o mundo e seus fenômenos, coconstruídas em nossas experiências resultantes de um processo interativo de interpretação e (re)significação" (BARCELOS, 2006, p.18). E como tal, elas são ao mesmo tempo individuais e sociais, dinâmicas, relacionadas ao contexto e paradoxais. 
Silva (2007, p. 250) acrescenta que: "[...] as crenças são interativas, emergentes, recíprocas, são vistas como sociais e, portanto, também cultural e historicamente constituídas através da interação do sujeito com o contexto". Assim sendo, as crenças são concebidas como formas de pensamento, construídas historicamente a partir da interação social.

Acerca das crenças sobre ensino e aprendizagem de línguas Barcelos (2007a), apresenta algumas reflexões sobre os estudos de Leite (2003) e de Kudiess (2005) por abordarem questões importantes relativas à forma como as crenças se agrupam, segundo uma organização psicológica, assemelhando-se a uma teia ou a um átomo. Assim, na perspectiva da Complexidade, o estudo das crenças exige um modelo de análise que considere a sua natureza complexa, tendo em vista que elas são construtos complexos, dinâmicos, interativos, emergentes, mediadas e ligadas à ação dos sujeitos.

Partindo desse entendimento, destacamos o modelo de organização sistêmica (belief systems) de Rokeach $(1968,1981)$ e a adaptação feita por Barcelos (2007b, p. 118) na área da LA. Esse modelo considera que as diversas crenças constitui um sistema que se estrutura como um átomo, cujo núcleo agrega diversas crenças centrais e, em torno destas, encontram-se as crenças periféricas (ROKEACH, 1968). Quanto mais central, mais importante é a função que a crença desempenha na vida do sujeito e, por isso, seria mais difícil mudá-la, repercutindo assim sobre as demais crenças.

Com relação à proposta de Rokeach (1981), as crenças centrais podem ser de dois tipos: consensuais, reforçadas por um consenso social unânime entre todas as referências de pessoas e grupos; e primitivas que se originam do encontro direto com o objeto da crença, portanto, não derivadas de outras crenças. As crenças periféricas podem ser classificadas em três tipos: crenças de autoridade, construídas a partir do contato com pessoas ou grupos que se tornam referências para o sujeito; crenças derivadas, originadas de outras crenças; e crenças inconsequentes, representadas por questões de gosto e identificação com o próprio objeto da crença.

Por essa classificação, as crenças centrais são mais resistentes à mudança, devido ao grande número de ligações com as outras crenças e em virtude das consequências funcionais resultantes desse encadeamento. Elas podem aprendidas pelo encontro direto com o objeto da crença ou reforçadas por pessoas e grupos em um consenso social; por outro lado, as crenças periféricas são arbitrárias e mantêm menos conexões com as outras crenças, por isso são mais suscetíveis à mudança (BARCELOS, 2007b).

Sob o prisma da organização sistêmica (belief systems), utilizamos o modelo adaptado por Barcelos (2007b) para compreendermos as crenças deste estudo, 
considerando a natureza sistêmica e a ação de alguns dos diversos agentes e fatores que se relacionam e influenciam as crenças dos formandos. Através do cruzamento de fatores, observamos as inter-relações estabelecidas entre as crenças sobre a variação linguística e as crenças sobre os seguintes aspectos linguísticos: lingua/linguagem, mitos linguísticos, diversidade linguística.

Para a análise do primeiro aspecto - língua/linguagem -, investigamos o conhecimento e os usos dos formandos acerca de três modelos teóricos sob os quais se abrigam diferentes outras crenças sobre língua/linguagem e seus usos: linguagem como expressão do pensamento, linguagem como instrumento de comunicação, e linguagem como forma de interação. Embora saibamos que existem outras concepções teóricas sobre o processamento da linguagem, reportamo-nos a esses modelos citados por Geraldi (1999) e por Travaglia (1997), tendo em vista que eles referenciados pelos próprios formandos durante seus depoimentos coletados durante as entrevistas.

Quanto ao segundo aspecto - mitos linguísticos -, restringimos à análise das crenças dos formandos acerca dos mitos listados por Bagno (2009) que foram identificados nos discursos de muitos formandos de Português e de Espanhol, a saber: mito 1 - "O português do Brasil apresenta uma unidade surpreendente"; mito 2 - "Brasileiro não sabe português/Só em Portugal se fala bem português"; mito 3 - "Português é muito difícil"; mito 4 - "As pessoas sem instrução falam tudo errado"; mito 5 - "O lugar onde melhor se fala português no Brasil é o Maranhão"; mito 6 - "O certo é falar assim porque se escreve assim"; mito 7 - "É preciso saber gramática para falar e escrever bem"; mito 8 - "O domínio da norma culta é um instrumento de ascensão social". Esses mitos linguísticos ${ }^{5}$ são algumas das muitas crenças que se criam sobre o uso da língua, sem que haja qualquer comprovação científica e geralmente, têm forte relação com muitos preconceitos linguísticos e sociais que circulam em nosso país e na área educacional.

No que diz respeito ao terceiro aspecto - diversidade linguística -, consideramos para análise das crenças, o conhecimento dos formandos relativo à natureza heterogênea das línguas. Nosso pensamento é que o reconhecimento da diversidade linguística como fator inerente às línguas pode revelar as crenças desses formandos sobre a variação linguística.

Nesta seção, discutimos o conceito de crenças na perspectiva da Complexidade, destacando o modelo de organização sistêmica e o recorte de análise dos aspectos linguísticos essenciais para a compreensão do nosso objeto de estudo, que é tão rico e, ao

\footnotetext{
${ }^{5}$ Neste estudo, os mitos linguísticos são concebidos como crenças de conotação negativa, fundamentadas em preconceitos sociais que são reproduzidos por diferentes grupos através de consensos coletivos. Segundo Aguilera (2008), a crença fundada no preconceito relaciona-se à identidade dos sujeitos, por isso reflete a intenção de preservar a identidade de si mesmo ou de um grupo social.
} 
mesmo tempo, complexo. A seguir, descreveremos os procedimentos metodológicos da pesquisa.

\section{METODOLOGIA}

Esta pesquisa inserida na área de Linguística Aplicada (LA) caracteriza-se como um estudo qualitativo realizado na perspectiva da Complexidade. Essa opção metodológica justifica-se pela complexidade e dinamicidade do objeto de análise, as crenças de formandos sobre a variação linguística.

A pesquisa foi realizada com formandos de dois cursos de letras (Letras Português e Letras Espanhol) da Universidade Estadual do Piauí (UESPI), localizada na cidade de Teresina, capital do Estado do Piauí (PI).

Ao todo, participaram do estudo vinte (20) formandos que cursavam o último período dos seus respectivos cursos de língua, destes, dez (10) eram discentes de Português e dez (10) de Espanhol. Esses sujeitos tiveram seus nomes preservados e são identificados no texto por codinomes.

Para o recorte apresentado neste artigo, apresentaremos dados coletados através aplicação de questionários (semi-abertos e entrevistas) sobre os três aspectos linguísticos: lingua/linguagem, mitos linguísticos, diversidade linguística. Mediante a comparação dos relatos e dos depoimentos coletados em campo e a consideração de fatores contextuais relativos ao universo de formação de professor de língua materna e estrangeira, cruzamos os dados com vistas à identificação das inter-relações desses fatores com as crenças sobre a variação linguística.

A discussão dos dados foi realizada com base na triangulação dos dados ${ }^{6}$. De acordo com Erickson (1988) a triangulação é o processo em que dados de diferentes naturezas são intercruzados, comparados e relacionados. Esse recurso analítico possibilita captar, através de vários procedimentos, as diferentes interpretações e perspectivas dos sujeitos pesquisados. No caso desta pesquisa, ele nos permitiu compreender a natureza complexa e dinâmica das crenças dos formandos.

\footnotetext{
${ }^{6}$ Denzin e Lincoln (2006) explicam que a triangulação de dados como uma alternativa para a validação da pesquisa, estratégia que acrescenta rigor, complexidade, riqueza e profundidade às investigações.
} 


\section{A ORGANIZAÇÃO SISTÊMICA DAS CRENÇAS}

Nesta seção, discutimos sobre a estruturação das crenças a partir do modelo de organização sistêmica (belief systems) para representar o sistema de crenças a partir dos fatores linguísticos analisados: lingua/linguagem, mitos linguísticos, diversidade linguística.

Analisando o aspecto língua/linguagem, encontramos algumas características das crenças centrais do tipo primitivas, ou seja, são aquelas das quais derivam outras crenças, tais como as crenças sobre alguns mitos linguísticos e sobre a variação linguística. Através dos relatos e dos depoimentos, constatamos que algumas crenças dos graduandos sobre mitos linguísticos relacionam-se às suas próprias crenças sobre língua/linguagem.

Relatos sobre o mito 3 - Português é muito difícil:

Ex: "Depende do grau de conhecimento de cada pessoa" (Aluno 5 do curso de português).

Ex: "São muitas regras e exceções" (Aluno 10 do curso de português).

Relatos sobre o mito 8 - O domínio da norma culta é um instrumento de ascensão social:

Ex: "A Língua formal é um importante instrumento no crescimento de todo cidadão" (Aluno 5 do curso de português).

Ex: "O uso da norma culta revela seres mais tendentes ascender socialmente" (Aluno 10 do curso de português).

Nesses exemplos, observamos que as crenças dos formandos 5 e 10 do curso de Português sobre os mitos 3 e 8 relacionam-se às crenças de linguagem como instrumento de comunicação. Elas são primitivas, adquiridas através do contato com o objeto da crença (com a língua) e associam o conhecimento da língua (enquanto sistema) à aprendizagem da gramática normativa do português. Assim, eles consideram que o domínio da norma culta essencial para comunicação e ascensão social, conforme se apresentam nos relatos desses e de outros formandos.

Segundo Barcelos (2007b), as crenças centrais possuem quatro características: (a) são mais interconectadas umas com as outras e, por esse motivo, se comunicam mais entre si e, dessa forma, trazem mais consequências para outras crenças; (b) estão mais relacionadas com a identidade; (c) são compartilhadas; (d) e derivam das experiências diretas ("ver para crer") dos sujeitos.

Ao definirem língua/linguagem, muitos dos formandos reafirmaram os pressupostos de um modelo teórico que tradicionalmente tem norteado o ensino de língua materna no Brasil e que privilegia a norma padrão - linguagem como instrumento de comunicação. 
Conforme Geraldi (1999) essa concepção de linguagem relaciona-se às teorias da comunicação e que, por isso, concebe a língua como um código ou conjunto de símbolos que se combinam segundo regras capazes de transmitir ao receptor determinada mensagem.

Quanto ao aspecto dos mitos linguísticos, encontramos algumas características das crenças do tipo consensuais, aquelas reforçadas pelo consenso entre os diversos grupos sociais. Como por exemplo, a referência ao mito 7 e ao mito 8, presentes, respectivamente, na maioria dos relatos dos alunos de Espanhol e de Português, conforme observamos a seguir:

Relatos sobre o mito 7 - "É preciso saber gramática para falar e escrever bem":

Ex: "[...] acredito que para falar bem deve-se ter no mínimo um conhecimento gramatical e a norma culta" (Aluno 1 do curso de espanhol).

Relatos sobre o mito 8 - "O domínio da norma culta é um instrumento de acessão social":

Ex: "Porque a escrita é uma variedade linguística de ascensão social e escrever bem é importantíssimo" (Aluno 3 do curso de português).

Nesses relatos, há evidências das crenças preconceituosas referentes aos mitos 7 e 8 foram construídas através de consensos entre os grupos sociais e reforçadas através da interação, de tal forma que elas passam a representar "verdades" básicas para esses sujeitos. Essa constatação reafirma algumas das características das crenças centrais, listadas por Barcelos (2007b), tais quais: relacionam-se à própria identidade de cada um, derivam da experiência direta desses sujeitos, além disso, são compartilhadas socialmente. Talvez por isso, até hoje, ainda há a divulgação de alguns mitos linguísticos, ou seja, de crenças preconceituosas, ainda que não tenham alguma comprovação científica, sobretudo, no universo da formação de professor de línguas (materna e estrangeira).

É pertinente salientarmos que, embora, muitos formandos tenham afirmado que discutiram bastante a questão da diversidade linguística no decorrer dos respectivos cursos, verificamos em muitos relatos a reprodução dos mitos 3, 7 e 8. Esses discursos preconceituosos reforçam outra crença, a de que existe "certo" e o "errado" quanto ao uso linguístico. Como o exemplo a seguir:

"O correto é fazer escrever correto devido a escrita ser uma variedade linguística de ascensão, sobre a fala você pode modelá-la de acordo como contexto em que se encontra" (Aluno 3 do curso de português).

Através dos depoimentos dos formandos dos dois cursos sobre a diversidade linguística, encontramos características de dois tipos de crenças periféricas apresentadas 
por Rokeach (1981), a saber: as crenças derivadas e as crenças de autoridade. Neste estudo, constatamos que algumas crenças dos formandos dos dois cursos sobre a diversidade foram originadas de algumas crenças centrais, como por exemplo, nos relatos dos formandos sobre o mito 1, identificamos evidências das crenças sobre variação linguística:

Relatos dos formandos sobre o mito 1 - "A língua portuguesa falada no Brasil apresenta uma unidade surpreendente":

"A Língua portuguesa falada no Brasil apresenta uma grande diversidade" (Aluno 5 do curso de português).

"A Língua Portuguesa no Brasil sofre variações de acordo com a região, a faixa etária, o sexo do falante, etc." (Aluno 10 do curso de português).

"Não, porque o português apresenta inúmeras variações" (Aluno 1 do curso de espanhol).

"A língua portuguesa apresenta uma grande variedade, por diversos fatores sociais, econômicos e regionais" (ALUNO 6 do curso de espanhol).

Esses relatos confirmam que as crenças periféricas podem derivar-se de outras crenças. Como ilustrado, as crenças de alguns formandos de Português e de Espanhol sobre a diversidade/variação linguística derivam da crença de que "Não existe uma unidade linguística no Português", ou seja, da discordância do mito 1.

Outra característica das crenças periféricas foi revelada pela constatação de que as crenças de alguns formandos foram provenientes das crenças em autoridade, ou seja, foram construídas através da interação social e/ou aceitas pelo processo de identificação ideológica. Essa característica foi identificada nas entrevistas realizadas com alunos dos dois cursos. Vejamos um exemplo dessas crenças de autoridade no depoimento de um aluno do curso de Letras-Português:

Ex: Eu lembro da Sintaxe, o professor Z, quando eles falavam do Português, ele dizia que também há professores estruturalistas que são muito apegados a gramática tradicional e querem que as pessoas imaginam, que as pessoas fala da maneira que é escrito no Português, ele sempre dizia, "ninguém fala da maneira que é escrita na gramática", nenhum brasileiro, ele exaltou isso muito bem na sala, "nenhum brasileiro fala de acordo com aquela gramática totalmente correta, vinte e quatro horas"(ALUNO 1 - LETRAS/PORTUGUÊS, grifo nosso).

Nos diálogos abaixo, um aluno do curso de Espanhol revela que sua crença sobre variação linguística foi influenciada pela interação com um professor, durante a Educação Básica:

ALUNO 7: Eu tive aula de espanhol desde o meu ensino fundamental na $5^{\mathrm{a}}$ série que é o $6^{\circ}$ ano agora e sempre a minha professora falou dessas variações, ela 
não falou todas, porque não tem como abordar todas na sala de aula, porém, ela sempre mostrou pra gente que existia a diferença e onde procurar.

PESQUISADORA: $E$ isso te ajudou a ter uma concepção sobre que é a diversidade de variação linguística, hoje?

ALUNO 7: Ajudou, porque criou em mim, pra não criar o preconceito de que existe uma unidade básica, uma unidade padrão e quando eu cheguei na universidade eu não me assustei tanto, porque existe já essas variações (grifos nossos).

Esses exemplos trazem evidências de que as experiências educacionais dos alunos e a ação de alguns fatores contextuais (como por exemplo, a interação entre professores e aluno) podem agir sobre o processo de fixação ou de mudança das crenças de alunos/formandos. Para Rokeach (1981), as crenças de autoridade são construídas através do contato, ou seja, da interação do sujeito com outras pessoas ou grupos sociais que são referências para ele, conforme ilustram também outros alunos.

Ao analisarmos todos os relatos dos formandos dos dois cursos sobre a variação linguística, observamos que, em meio à diversidade das definições expressas pelos alunos, praticamente todos eles conceberam a variação linguística como um fenômeno natural inerente às línguas e decorrente de fatores históricos, geográficos, socioculturais, etc. Logo abaixo, destacamos algumas definições expressas pelos alunos dos dois cursos sobre a variação linguística:

\footnotetext{
"Variação linguística a uma forma diferente de se falar algo. Alguns fatores que 'interferem' na variação são idade, escolaridade, classe social, região do falante, entre outros" (ALUNO 1 - LETRAS/ESPANHOL, grifo nosso).
}

\begin{abstract}
"As variações linguísticas são diversas formas de se falar a mesma língua, dependendo de vários aspectos, principalmente sociais" (ALUNO 4 LETRAS/ESPANHOL, grifo nosso).
\end{abstract}

"A diversidade linguística é a heterogeneidade da linguagem, as diversas formas que pode desenvolver a linguagem dependendo do contexto social ao qual está inserido". (ALUNO 6 - LETRAS/ESPANHOL, grifo nosso).

"As diversas formas de dizer a mesma coisa a partir de estudos que levem em consideração a idade, a escola, cidades, local de residência" (ALUNO 2 LETRAS/PORTUGUÊS, grifo nosso).

"São formas diferentes de se expressar, provem de regiões diferentes do Brasil" (ALUNO 6 - LETRAS/PORTUGUES, grifo nosso).

A maioria dos alunos destacou os fatores que influenciam a variação, a saber: fatores socioculturais, fatores geográficos e fatores históricos. Essas definições estão em consonância com o conceito apresentado por Tarallo (1985), para o qual as variantes linguísticas representam as diferentes formas de se dizer algo em um mesmo contexto e com o mesmo valor de verdade. Sendo assim, constatamos que os alunos fundamentaram suas crenças nos pressupostos da Sociolinguística Variacionista, uma vez que a explicação 
desse fenômeno emerge nos usos da língua e, por isso, são influenciados pelos fatores externos ao sistema linguístico e não somente pelos fatores internos. Porém, algumas das definições dos graduandos sobre a variação linguística revelaram como essa questão ainda não estava bem esclarecida, especialmente, para três (03) alunos do curso de LetrasPortuguês e um (01) aluno de Letras-Espanhol, isso sugere que essas crenças estejam passando por um processo de mudança e/ou adaptação.

Segundo o modelo de organização das crenças e sua dimensão periférico-central verificamos que as crenças dos formandos de Português e de Espanhol sobre língua/linguagem e mitos linguísticos encontram-se na base da constituição das crenças de cada aluno; enquanto que as crenças sobre diversidade e variação linguística estão na parte mais periférica dos sistemas de crenças.

As crenças dos formandos sobre o aspecto língua/linguagem parecem funcionar como base para as convicções que se criam em torno das línguas, seja ela materna ou estrangeira. Dito de outra maneira, essas crenças presentes na base (parte central) do sistema de crenças, exercem influências sobre as demais crenças.

Nos relatos e nos depoimentos dos formandos de Português e Espanhol encontramos evidências de que as crenças preconceituosas (mitos 3, 7 e 8) parecem estar relacionadas às crenças desses formandos sobre linguagem como instrumento de comunicação social. Essa constatação corrobora com Barcelos (2007b) para a qual, as crenças centrais estão diretamente relacionadas umas às outras e se comunicam mais entre si e, dessa maneira, trazem mais consequências para as outras crenças.

No que diz respeito às crenças dos graduandos sobre a questão da diversidade linguística, identificamos que, boa parte delas foram construídas e/ou (re)construídas no âmbito da formação de professores de línguas (materna e estrangeira). Essas crenças sofrem muita influência da ação de fatores ligados aos processos de ensino/aprendizagem de língua materna (LM) e de língua estrangeira (LE).

Sob a perspectiva de análise adotada neste estudo foi possível compreender a natureza sistêmica das crenças sobre a variação linguística, em virtude de sua complexidade, as ligações entre os componentes dos sistemas são flexíveis, portanto, alteram-se constantemente ao longo do tempo e do espaço, de forma imprevisível e não linear, uma vez que os esses sistemas não respondem passivamente às eventuais mudanças, caracterizando assim, a imprevisibilidade e não linearidade dos sistemas complexos como pondera Larsen-Freeman (1997). 
As crenças que aparentemente estão desordenadas estruturam-se em redes e "teias", distribuídas de forma gradiente: mais centralizadas ou mais periféricas, conforme figura abaixo:

\section{Figura 1- Natureza sistêmica das crenças}

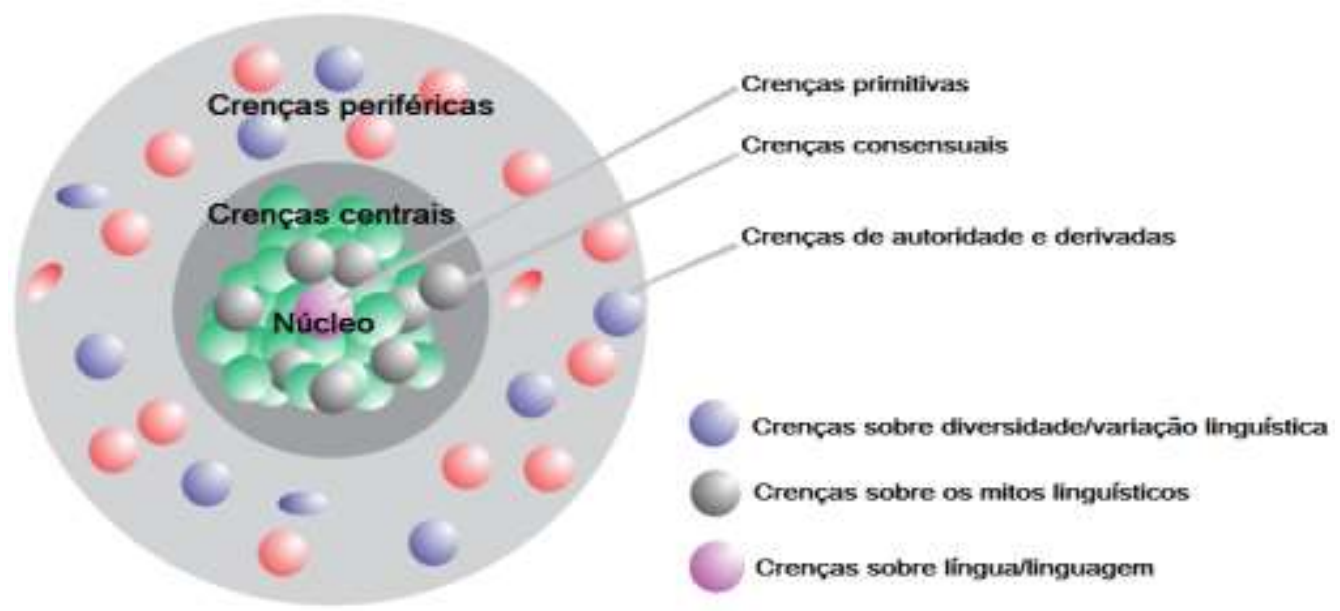

Fonte: A autora (2014).

A triangulação dos dados revelou a presença de algumas características dos sistemas de crenças, já mencionadas por Rokeach (1981) e Barcelos (2007b). Na parte central do gradiente, encontram-se as crenças sobre língua/linguagem (do tipo primitiva), aquelas que estão no núcleo do sistema e sobre as quais derivam outras crenças, inclusive sobre alguns mitos linguísticos (do tipo consensuais). Na parte mais periférica, estão as crenças sobre a diversidade e variação linguística (do tipo derivada e do tipo de autoridade); essas crenças sofrem interferências de fatores relacionados à formação de professor de língua materna (LM) e de língua estrangeira (LE).

\section{CONSIDERAÇÕES FINAIS}

Neste estudo, encontramos evidências da natureza sistêmica das crenças relativos à língua/linguagem, aos mitos linguísticos e à variação linguística. A análise das crenças de formandos de Português e de Espanhol revelou identidade entre elas, ou seja, padrões semelhantes foram encontrados em meio à diversidade das crenças dos graduandos dos dois cursos de formação de professores.

Observamos que as crenças possuem natureza complexa, dinâmica e sistêmica. De tal modo que, as crenças dos formandos sobre a variação linguística relacionam-se às crenças sobre língua/linguagem, mitos linguísticos e diversidade linguística, constituindo 
sistemas de crenças organizados, estruturalmente, em "teias" mais centrais e mais periféricas,

As crenças sobre língua/linguagem e sobre os mitos linguísticos relacionam-se umas às outras, exercendo algum tipo influência sobre as demais. Muitas delas encontram-se "enraizadas" no sistema de crenças de cada aluno e são mais resistentes à mudança. Por sua vez, as crenças sobre variação linguística são mais suscetíveis à reflexão, isto é, são mais fáceis de serem reconstruídas, especialmente no âmbito do sistema de formação de professor de línguas (materna e estrangeira).

\section{REFERÊNCIAS}

AGUILERA, V. A. Crenças e atitudes linguísticas: o que dizem os falantes das capitais brasileiras. Estudos Linguísticos (São Paulo), v. 2, p. 105-112, 2008.

AUGUSTO, R. C. O processo de desenvolvimento da competência linguística em inglês na perspectiva da complexidade. In: PAIVA, V. M. O.; NASCIMENTO, M. Sistemas Adaptativos Complexos: Lingua(gem) e Aprendizagem. Belo Horizonte: Faculdade de Letras da UFMG, 2009.

BRAGA, J. C. F. A presença cognitiva em comunidades de aprendizagem on-lin. In: PAIVA; V. L . O.; NASCIMENTO, M. (orgs.) Sistemas Adaptativos Complexos: linguagem e aprendizagem. Belo Horizonte: Faculdade de Letras da UFMG, 2009.

Comunidades autônomas de aprendizagem on-line na perspectiva da complexidade. Tese (Doutorado em Estudos Linguísticos) - Faculdade de Letras da Universidade Federal de Minas Gerais, Belo Horizonte, 2007.

BAGNO, M. Preconceito Linguístico: o que é, como se faz. 51 ed. São Paulo: Edições Loyola, 2009.

BARCELOS, A. M. F. Revisitando os conceitos de cultura de aprender e de ensinar. In: SANTOS, S. C. K.; MOZZILLO, I. (Orgs.). Cultura e diversidade na sala de aula de língua estrangeira. Pelotas: UFPEL, 2008.

Reflexões acerca da mudança de crenças sobre ensino e aprendizagem de

línguas. Revista Brasileira de Linguística Aplicada. v.7, n.2, 2007b. 
Crenças sobre ensino e aprendizagem de línguas: reflexões de uma década de pesquisa no Brasil. In: ALVAREZ, M. L. O.; SILVA, K. (orgs). Linguística Aplicada: Múltiplos Olhares, Campinas: Pontes, 2007a.

Cognição de professores e alunos: tendências recentes na pesquisa de crenças sobre ensino e aprendizagem de línguas. In: BARCELOS, A. M. F.; VIEIRA-ABRAHÃO, M. H. (Orgs.). Crenças e ensino de línguas: foco no professor, no aluno e na formação de professores. Campinas: Pontes, 2006, p. 15-4.

BORGES, S. S; FRAGA, L. Crenças de formandos de Letras sobre aprendizagem de inglês. In: Anais do I Colóquio Internacional de Estudos Linguísticos e Literários. UEM, Junho de 2010.

DENZIN, N. K.; LINCOLN, Y. S. A disciplina e a prática da pesquisa qualitativa. In: . (orgs.). $O$ planejamento da pesquisa qualitativa: teorias e abordagens.

Porto Alegre: Artmed, 2006.

ERICKSON, F. Ethnographic description in Sociolinguistics. Berlin e N. York: Walter de Gruyter, 1988. p.95-108.

GERALDI, João Wanderley (Org.). O texto na sala de aula. 3. ed. São Paulo: Ática, 1999.

GOMES, Y. L. S. Crenças e variação linguística: uma abordagem sistêmica na perspectiva da complexidade. Teresina: EDUFPI, 2015.

KUDIESS, E. As crenças e o sistema de crenças do professor de inglês sobre o ensino e a aprendizagem da língua estrangeira no sul do Brasil: sistema, origens e mudanças.

Linguagem e Ensino, Pelotas, v. 8, n. 2, p. 39-96, 2005.

LARSEN-FREEMAN, D. Chaos/complexity science and second language acquisition Applied Linguistics. Oxford: Oxford University Press, v.2, n.18, p.141-165, 1997.

LEFFA, V. J. Transdisciplinaridade no ensino de línguas: a perspectiva das Teorias da Complexidade. Revista Brasileira de Linguística Aplicada, v.6, n.1, p.27-49, 2006.

LEITE, E. F. O. Crenças: um portal para o entendimento da prática de uma professora de inglês como língua estrangeira. Dissertação (Mestrado em Letras). PUC, Rio de Janeiro, 2003. 
MARIOTTI, H. Complexidade e pensamento complexo: breve introdução e desafios actuais. Rev. Port. Clin. Geral. n.23, p.727-31, 2007.

MARTINS, A. C. S.; BRAGA, J. C. F. Caos, complexidade e Linguística Aplicada: diálogos transdisciplinares. Rev. Brasileira de Linguística Aplicada, v.7, n.2, 2007.

MASON, M. What Is Complexity Theory and what are its implications for educational change? Educational Philosophy and Theory, v.40, n.1, p.35-49, 2008.

OLIVEIRA, R. A. Complexidade: conceitos, origens, afiliações e evoluções. In: PAIVA, V. M. O.; NASCIMENTO, M. (Org.) Sistemas Adaptativos Complexos: Lingua(gem) e Aprendizagem. Belo Horizonte: Faculdade de Letras da UFMG, 2009.

PAIVA, V. L. M. O. O Modelo fractal de aquisição de línguas. In: BRUNO, F. C. (Org.). Reflexão e prática em ensino/aprendizagem de língua estrangeira. São Paulo: Clara Luz, 2005. p.23-36.

RESENDE, L. A. S. Identidade e aprendizagem de inglês sob a ótica do caos e dos sistemas complexos (Tese de Doutorado em Estudos Linguísticos) - Faculdade de Letras da UFMG, Belo Horizonte, 2009.

ROKEACH, M. Crenças, atitudes e valores. Trad.de Angela M. M. Barbosa. Rio de Janeiro: Ed. Interciência, 1981.

Beliefs, attitudes, and values: A theory of organization and change. San Francisco: Jossey-Bass, 1968.

SABOTA, B. Estágio Supervisionado de LE: um estudo de caso sobre a formação universitária de professores de inglês na UFG. Tese (Doutorado em Letras e Linguística) - Faculdade de Letras, Universidade Federal de Goiás, Goiânia, 2008.

SADE, L. A. Complexity and identity reconstruction in second language acquisition. RBLA, Belo Horizonte, v. 9, n. 2, p. 515-537, 2009.

SILVA, K. A. Crenças sobre o ensino e aprendizagem de línguas na Linguística Aplicada: um panorama histórico dos estudos realizados no contexto brasileiro. Revista Linguagem \& Ensino, v.10, n.1, p.235-271, jan./jun.2007.

TARALLO, F. A relação entre língua e sociedade. In: sociolinguística. São Paulo: Ática, 1985. 
TRAVAGLIA, L. C. Gramática e interpretação: uma proposta para o ensino de gramática no $1^{\circ}$ e $2^{\circ}$ graus. 2 ed. São Paulo: Cortez, 1997. 